\title{
Maternal Circulating Concentrations of Tumor Necrosis Factor-Alpha, Leptin, and Adiponectin in Gestational Diabetes Mellitus: A Systematic Review and Meta-Analysis
}

\author{
Jie Xu, ${ }^{1}$ Yan Hong Zhao, ${ }^{2}$ Yun Ping Chen, ${ }^{1}$ Xiao Lei Yuan, ${ }^{3}$ Jiao Wang, ${ }^{1}$ \\ Hui Zhu, ${ }^{1}$ and Chun Mei Lu' \\ ${ }^{1}$ Harbin Medical University, 157 Baojian Road, Nangang District, Harbin, Heilongjiang 150081, China \\ ${ }^{2}$ First Affiliated Hospital of Harbin Medical University, 199 Dazhi Street, Nangang District, Harbin, Heilongjiang 150001, China \\ ${ }^{3}$ Second Affiliated Hospital of Harbin Medical University, 148 Baojian Road, Nangang District, Harbin, Heilongjiang 150081, China \\ Correspondence should be addressed to Hui Zhu; dzhuhui@aliyun.com and Chun Mei Lu; angel200202003@163.com
}

Received 4 May 2014; Revised 4 July 2014; Accepted 18 July 2014; Published 19 August 2014

Academic Editor: José L. Bartha

Copyright (C) 2014 Jie Xu et al. This is an open access article distributed under the Creative Commons Attribution License, which permits unrestricted use, distribution, and reproduction in any medium, provided the original work is properly cited.

\begin{abstract}
Gestational diabetes mellitus (GDM) is one of the most common pregnancy complications. Inflammation may play a role in the pathogenesis of GDM. We performed a systematic review and meta-analysis to determine whether maternal serum concentration of tumor necrosis factor-alpha (TNF- $\alpha$ ), leptin, and adiponectin were associated with GDM. A systematic search of PubMed and Medline was undertaken. In total, 27 trials were evaluated by meta-analyses using the software Review Manager 5.0. The results showed that maternal TNF- $\alpha(P=0.0003)$ and leptin $(P<0.00001)$ concentrations were significantly higher in GDM patients versus controls. However, maternal adiponectin $(P<0.00001)$ concentration was significantly lower in GDM patients compared with controls. Subgroup analysis taking in consideration the effect of obesity on maternal adipokine levels showed that circulating levels of TNF- $\alpha$ and leptin remained elevated in GDM patients compared to their body mass index (BMI) matched controls, and adiponectin level remained depressed in GDM individuals. Our findings strengthen the clinical evidence that GDM is accompanied by exaggerated inflammatory responses.
\end{abstract}

\section{Introduction}

Gestational diabetes mellitus (GDM), which is defined as impaired glucose tolerance with onset or first recognition during pregnancy, is one of the most common pregnancy complications and affects approximately $3-8 \%$ of all pregnancies $[1,2]$. GDM develops when the maternal insulin supply is not sufficient to compensate for decreased insulin sensitivity during pregnancy. Although the detailed mechanism of how GDM happens remains poorly known, GDM could lead to various adverse outcomes on pregnant women and their offspring, such as gestational hypertension, cesarean delivery, preterm birth, and macrosomia, as well as the predisposition to the development of metabolic syndrome and type 2 diabetes [2].

In recent years, clinical and epidemiological studies have described a clear connection between the development of low-grade inflammatory responses and metabolic diseases, including obesity, type 2 diabetes, and GDM, characterized by secretion of upregulated inflammatory mediators [3]. Particularly inflammatory cytokines have been suspected to be important contributors to the pathogenesis of metabolic dysregulation. Most cytokines, such as tumor necrosis factoralpha (TNF- $\alpha$ ), interleukin-6 (IL-6), and leptin, are proinflammatory. Among these proinflammatory cytokines, TNF$\alpha$ and leptin have been suggested as the strongest predictors of pregnancy-associated insulin resistance $[4,5]$. One prominent exception is adiponectin, an anti-inflammatory adipokine that promotes insulin sensitization [6].

GDM is thought to be partly attributed to secretion of upregulated inflammatory cytokines from gestational tissues that accelerate insulin resistance [7]. Among these cytokines, extensive attention has been given to TNF- $\alpha$, leptin, and adiponectin. TNF- $\alpha$ is one of candidate molecules 
responsible for causing insulin resistance during pregnancy. It has been suggested that TNF- $\alpha$ is a predictor of insulin resistance in human pregnancy [4]. During late pregnancy, TNF- $\alpha$ is inversely correlated with insulin sensitivity. Neutralization of the TNF- $\alpha$ signaling leads to an improvement in insulin sensitivity [8]. Leptin plays a key role in the energy intake and energy expenditure and is said to have proinflammatory activities. In healthy pregnancies, the maternal serum leptin level is in a negative linear correlation with the head circumference of the newborns. In GDM pregnancies, an inverse relationship is shown between the body length, head circumference, and body weight of the newborns and the maternal leptin concentration [9]. Increased leptin levels may contribute to insulin resistance in GDM and in the third trimester of normal pregnancy [9]. On the other hand, adiponectin, one of a smaller number of anti-inflammatory factors, is thought to have beneficial effects on insulin sensitivity and anti-inflammation. It stimulates glucose uptake in skeletal muscle by activating AMP-activated protein kinase [10], and administration of adiponectin to diabetic mice has been shown to enhance insulin activity [11]. In previously published studies, circulating levels of leptin, adiponectin, and TNF- $\alpha$ in the early pregnancy closely predict the development of GDM.

Many studies have reported on the maternal serum concentrations of cytokines in GDM patients. However, conflicting results are available in the literature about the association of cytokines and GDM. To our knowledge, there remains a lack of systematic reviews and meta-analysis on the relationship between GDM and maternal circulating concentrations of cytokines. Therapeutic strategies based on imbalance of proinflammatory and anti-inflammatory cytokines for preventing or treating metabolic dysfunction in GDM should be based on evidence.

In the present study, we did a systematic review and metaanalysis of published data in accordance with the preferred reporting items for systematic reviews and meta-analysis (PRISMA) statement [12]. Our objective was to address the association of maternal circulating levels of cytokines (TNF$\alpha$, leptin, and adiponectin) and GDM.

\section{Methods}

2.1. Literature Search and Data Extraction. Our research protocol included the detailed research question, search strategy, and screening criteria. The detailed research question was composed of the patient, intervention, comparator, outcome, and study design (PICOS) approach.

The search data sources were Pubmed and Medline between 1966 and 2012.1 The search key words consisted of "gestational diabetes mellitus or GDM," "tumor necrosis factor alpha," “TNF- $\alpha$," "leptin," and "adiponectin." In addition, all references cited in the found studies were reviewed to identify additional studies.

After screening the database search results, full-text assessment was done for study selection. The following information was extracted into a computer-based spreadsheet: authors, year of publication, and clinical data. For continuous outcomes, information on the numbers of cases and controls, maternal plasma mean concentrations of TNF$\alpha$, leptin, and adiponectin, and standard difference (SD) was also abstracted. Jie $\mathrm{Xu}$ and Yan Hong Zhao established the research protocol, and database searches were conducted independently by Yun Ping Chen and Xiao Lei Yuan. Any inconsistencies were resolved by discussions with the 3rd reviewer, Jiao Wang.

2.2. Inclusion Criteria. The PICOS research question was a foundation for study selection. Eligible studies had to meet the following criteria: (1) with cytokine concentrations as the exposure and GDM as the outcome, either cross-sectional or prospective case controlled design is accepted for concentration detection studies; (2) the study should contain original data; (3) maternal blood was the object or one of the objects of study for concentration detection, and maternal blood was collected in the late-second or third trimester of pregnancy; (4) for concentration detection, plasma concentrations of TNF- $\alpha$, leptin, or adiponectin for GDM and control groups were available or could be provided as mean $( \pm S D)$. GDM was diagnosed if patients met at least two of the following four diagnostic criteria [37]: fasting plasma glucose (FPG) $\geq 95 \mathrm{mg} / \mathrm{dL}$; glucose level at 1, 2, and 3 hours after meals $\geq 180 \mathrm{mg} / \mathrm{dL}, \geq 155 \mathrm{mg} / \mathrm{dL}$, and $\geq 140 \mathrm{mg} / \mathrm{dL}$, respectively. Controls were normal glucose tolerance pregnant women. Thus, review articles, records published in languages other than English, and studies measuring cytokine concentrations from placenta, peripheral blood cells, amnionic fluid, cord blood, or serum sample following stimulation or sample collected in the nonpregnant period were excluded due to the lack of comparability. Moreover, studies with case-only or with data unclear or provided in forms other than mean $( \pm S D)$ were ruled out as methodological reason.

2.3. Quality Assessment. The quality of the primary studies was assessed using Newcastle-Ottawa Quality Assessment Scale (NOS) with some modifications to match the needs of this study. Items assessed included three items: patient selection, comparability of GDM and control groups, and assessment of exposure. A study can be awarded a maximum of one star for each numbered item within the selection and exposure categories. A maximum of two stars can be given for comparability. Studies were graded on an ordinal star scoring scale with higher scores representing studies of higher quality. The quality of each study was graded as either level 1 ( 0 to 5 ) or level 2 (6 to 9) [38].

2.4. Publication Bias. Publication bias was assessed by a Funnel plot asymmetry test.

2.5. Evaluation of Statistic Association. We performed power calculations with $\mathrm{G}^{*}$ Power program version 3.0 [39]. Statistics were performed with Review Manager 5.0 (Cochrane Collaboration, Oxford, United Kingdom). The inverse variance method was adopted for continuous data meta-analysis with a weighted mean difference (WMD) and 95\% CI. The level of heterogeneity between studies was tested graphically on Forest plots and statistically using Cochran's chi-square 


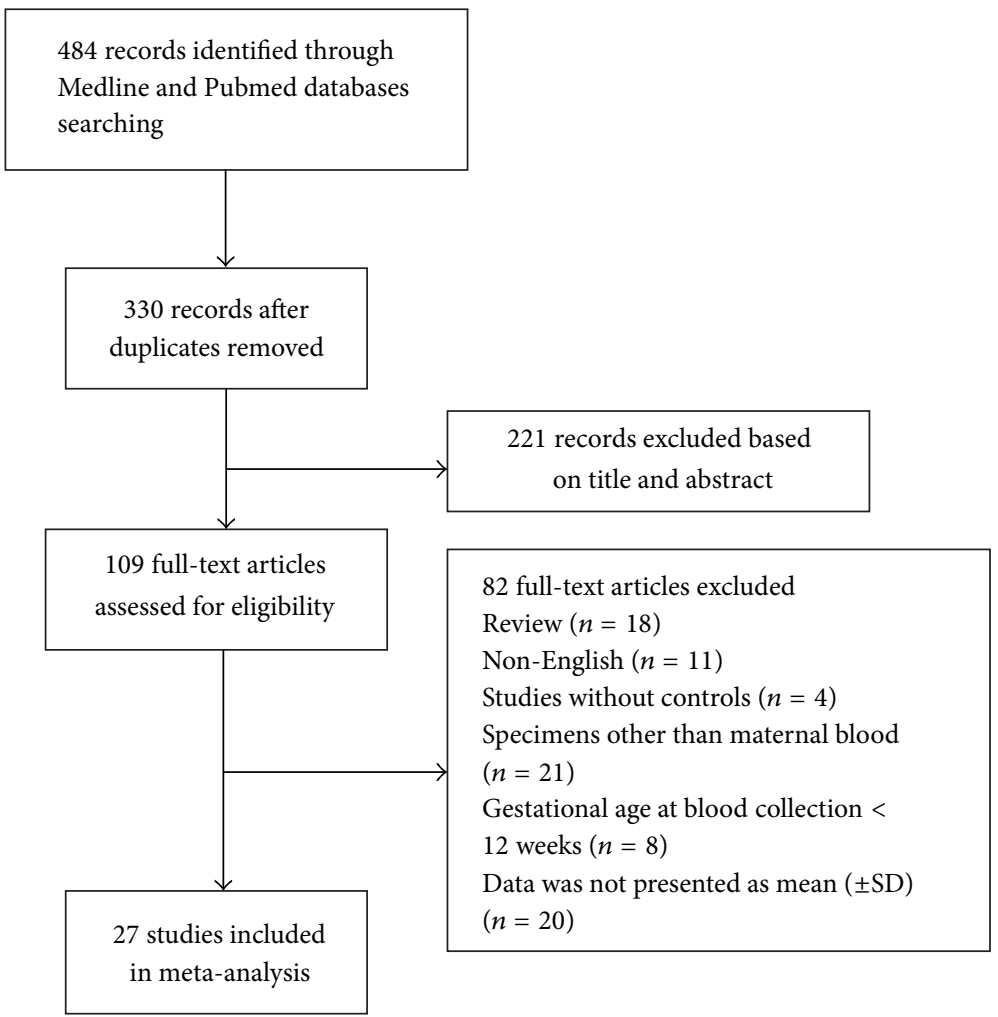

FIGURE 1: Flow diagram of the selection and systematic review of studies.

analysis and indicated intuitively by an $I^{2}$ index. $I^{2}>50 \%$ suggested heterogeneity. As recommended by Song et al. [40], $P<0.1$ was used as the cut-off for significance of heterogeneity and using random effects model; otherwise, fixed effects model was used.

\section{Results}

3.1. Quality Control. Database search identified 484 potentially relevant records, of which 109 full-text articles were assessed for eligibility (Figure 1). In total, 82 articles were excluded for the reasons given in Figure 1. Thus, only 27 studies were used for meta-analysis, which included 10 for TNF- $\alpha$ concentrations $[4,7,9,13-19], 18$ for leptin concentrations $[4,7,9,14,15,17,18,20-30]$, and 15 for adiponectin concentrations $[13,14,16-18,22,23,25,29,31-36]$. The characteristics of the trials included in the meta-analysis were summarized in Table 1.

The quality assessment and scores of these studies were presented in Table 2. Among these studies, 11 studies had a quality score of $7[4,9,14,20,21,28,30-32,34,35], 14$ studies scored 6 [7, 13, 15-19, 22-24, 26, 27, 29, 36], and 2 studies scored $5[25,33]$, which illustrated that the methodological quality was generally good.

The power of our sample size for meta-analysis of continuous outcome to detect correlation between TNF- $\alpha$, leptin, and adiponectin maternal serum level and GDM was $95.0 \%$, 99.6\%, and 99.7\% $(\alpha=0.05$, effect size index $=0.2$, small effect convention for continuous data), respectively.
3.2. Heterogeneity and Publication Bias. For TNF- $\alpha$, leptin, and adiponectin concentration detection, different studies used enzyme-linked immunosorbent assay (ELISA) kits from different suppliers. Significant heterogeneity was observed in all sub-meta-analyses (Table 3 ). This justified the adoption of random effects model in all analyses. Publication bias was not observed except in the outcome of TNF- $\alpha$ concentration meta-analysis, as demonstrated by the funnel plots (see Supplementary Material available online at http://dx.doi.org/10.1155/2014/926932).

3.3. Serum TNF- $\alpha$ Concentration and GDM. Meta-analysis of maternal TNF- $\alpha$ level was comprised of 10 studies with 12 comparisons, as Gauster et al. and Kirwan et al. divided the control subjects into lean and obese group. There was significantly elevated TNF- $\alpha$ concentration in serum of GDM patients versus normal pregnancies with an overall WMD of $6.22 \mathrm{pg} / \mathrm{mL}$ (95\% CI [2.84, 9.60], $P=0.0003$ ) (Figure 2).

Because obesity is associated with insulin resistance and an increased risk of GDM, we also examined the effect of obesity on plasma TNF- $\alpha$ level. We categorized the studies according to their design into two classes with body mass index (BMI) matched and BMI not matched between control and GDM. Plasma TNF- $\alpha$ concentrations remained significantly higher in GDM patients compared to their BMI matched control subjects $(P=0.002,[\mathrm{WMD}]=2.08 \mathrm{pg} / \mathrm{mL}$, $95 \%$ CI $[0.75,3.41] \mathrm{pg} / \mathrm{mL})$.

3.4. Serum Leptin Concentration and GDM. Leptin measurements of 568 GDM patients and 773 controls were extracted 


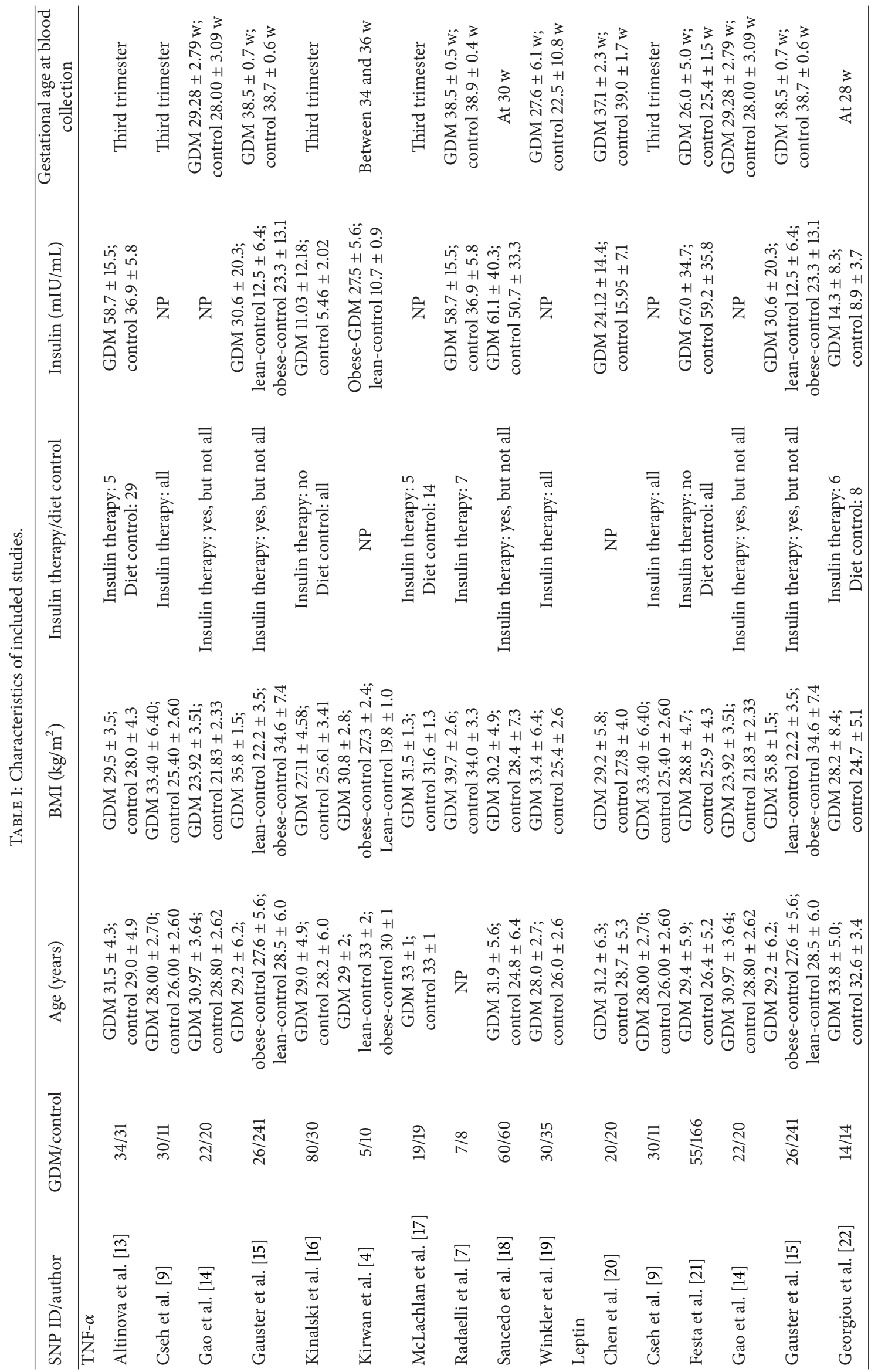




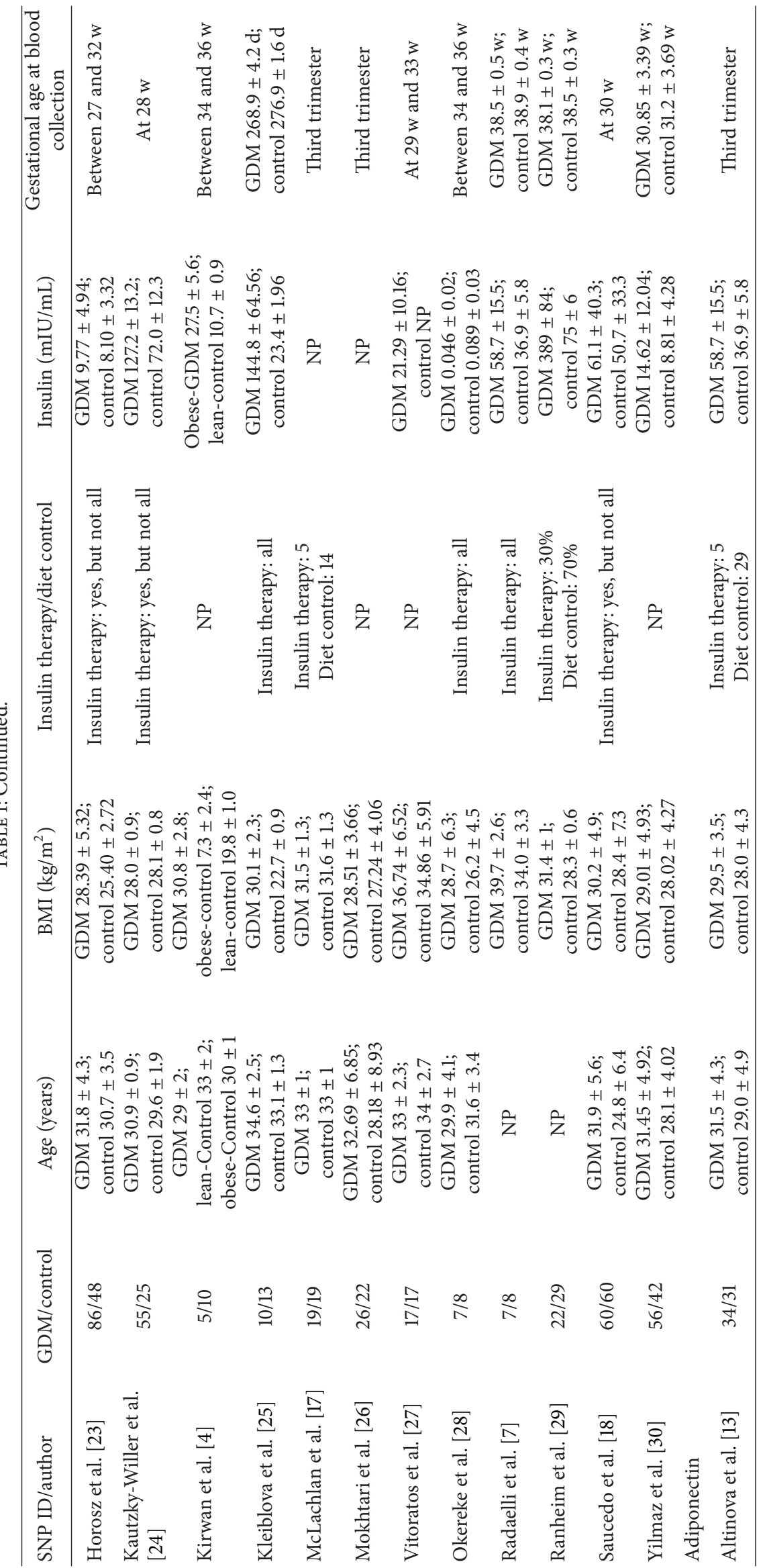




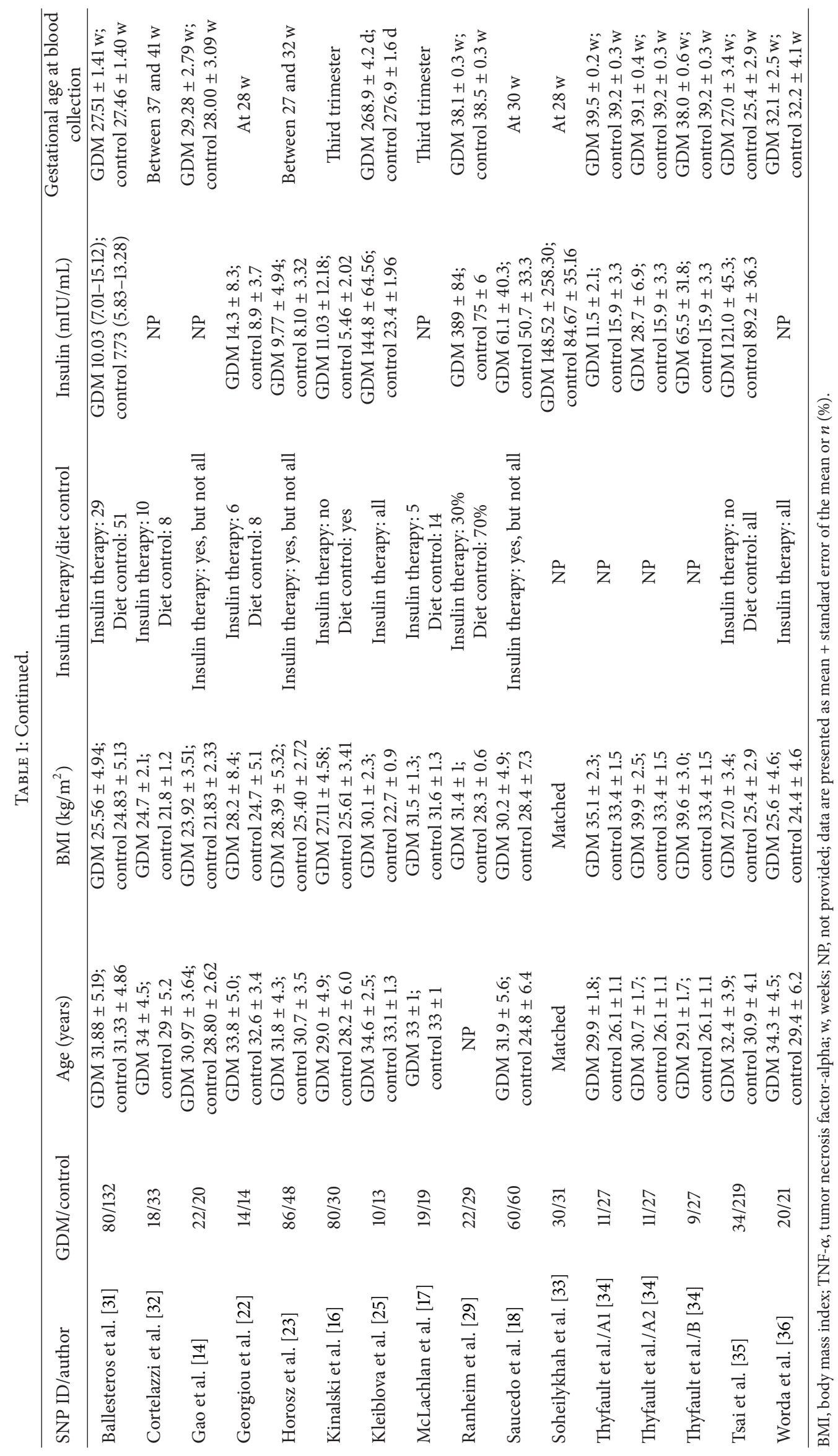


TABLE 2: Assessment of study quality.

\begin{tabular}{|c|c|c|c|c|c|c|c|c|c|c|}
\hline \multirow{2}{*}{ Authors } & \multirow{2}{*}{ Year } & \multicolumn{4}{|c|}{ Selection } & \multirow{2}{*}{$\begin{array}{c}\text { Comparability } \\
5 \\
\end{array}$} & \multicolumn{3}{|c|}{ Exposure } & \multirow{2}{*}{ Score } \\
\hline & & 1 & 2 & 3 & 4 & & 6 & 7 & 8 & \\
\hline Cseh et al. [9] & 2002 & $*$ & * & & * & $* *$ & $*$ & $*$ & & $* * * * * * *$ \\
\hline Gao et al. [14] & 2008 & $*$ & $*$ & & $*$ & $* *$ & $*$ & $*$ & & $* * * * * * *$ \\
\hline Kirwan et al. [4] & 2002 & $*$ & * & * & * & $* *$ & & $*$ & & $* * * * * * *$ \\
\hline Chen et al. [20] & 2010 & $*$ & * & & $*$ & $* *$ & $*$ & * & & $* * * * * * *$ \\
\hline Festa et al. [21] & 1999 & $*$ & * & & * & $* *$ & $*$ & $*$ & & $* * * * * * *$ \\
\hline Okereke et al. [28] & 2004 & $*$ & $*$ & * & * & $* *$ & $*$ & $*$ & & $* * * * * * *$ \\
\hline Yilmaz et al. [30] & 2010 & $*$ & * & & * & $* *$ & $*$ & * & & $* * * * * * *$ \\
\hline Ballesteros et al. [31] & 2011 & $*$ & $*$ & & * & $* *$ & $*$ & $*$ & & $* * * * * * *$ \\
\hline Cortelazzi et al. [32] & 2007 & $*$ & $*$ & & $*$ & $* *$ & $*$ & $*$ & & $* * * * * * *$ \\
\hline Thyfault et al. [34] & 2005 & $*$ & $*$ & & * & $* *$ & $*$ & * & & $* * * * * * *$ \\
\hline Tsai et al. [35] & 2005 & $*$ & $*$ & & * & $* *$ & $*$ & $*$ & & $* * * * * * *$ \\
\hline Altinova et al. [13] & 2007 & $*$ & & & * & $* *$ & $*$ & $*$ & & $* * * * * *$ \\
\hline Gauster et al. [15] & 2011 & $*$ & & & * & $* *$ & $*$ & $*$ & & $* * * * * *$ \\
\hline Kinalski et al. [16] & 2005 & $*$ & & & $*$ & $* *$ & $*$ & $*$ & & $* * * * * *$ \\
\hline McLachlan et al. [17] & 2006 & $*$ & & & * & $* *$ & $*$ & $*$ & & $* * * * * *$ \\
\hline Radaelli et al. [7] & 2003 & $*$ & $*$ & & & $* *$ & $*$ & $*$ & & $* * * * * *$ \\
\hline Ranheim et al. [29] & 2004 & $*$ & & & * & $* *$ & * & * & & $* * * * * *$ \\
\hline Saucedo et al. [18] & 2011 & $*$ & & & * & $* *$ & $*$ & $*$ & & $* * * * * *$ \\
\hline Winkler et al. [19] & 2002 & $*$ & & & * & $* *$ & $*$ & $*$ & & $* * * * * *$ \\
\hline Georgiou et al. [22] & 2008 & $*$ & $*$ & & & $* *$ & $*$ & $*$ & & $* * * * * *$ \\
\hline Horosz et al. [23] & 2011 & $*$ & & & $*$ & $* *$ & $*$ & $*$ & & $* * * * * *$ \\
\hline Kautzky-Willer et al. [24] & 2001 & $*$ & & & * & $* *$ & * & $*$ & & $* * * * * *$ \\
\hline Mokhtari et al. [26] & 2011 & $*$ & $*$ & & * & * & $*$ & * & & $* * * * * *$ \\
\hline Vitoratos et al. [27] & 2001 & $*$ & & & * & $* *$ & $*$ & $*$ & & $* * * * * *$ \\
\hline Worda et al. [36] & 2004 & $*$ & * & & * & $*$ & $*$ & $*$ & & $* * * * * *$ \\
\hline Kleiblova et al. [25] & 2010 & $*$ & & & & $* *$ & $*$ & $*$ & & $* * * * *$ \\
\hline Soheilykhah et al. [33] & 2009 & $*$ & & & $*$ & $* *$ & & $*$ & & $* * * * *$ \\
\hline
\end{tabular}

TABLE 3: Summary of heterogeneity of these meta-analyses.

\begin{tabular}{lcccr}
\hline Outcome & $N(\mathrm{GDM}$, control $)$ & Heterogeneity $\chi^{2}(P$ value $)$ & Inconsistency $I^{2}(\%)$ & Analysis model \\
\hline TNF- $\alpha$ level & $880(344,536)$ & $19225.30(P<0.00001)$ & 94 & Random model \\
Leptin level & $1341(568,773)$ & $333.69(P<0.00001)$ & 94 & Random model \\
Adiponectin level & $1341(560,781)$ & $282.81(P<0.00001)$ & Random model \\
\hline
\end{tabular}

from 18 studies with 20 comparisons, as Gauster et al. and Kirwan et al. divided the control subjects into lean and obese group. GDM patients had significantly higher serum leptin concentration with an overall WMD of $7.52 \mathrm{ng} / \mathrm{mL}$ (95\% CI $[4.79,10.25], P<0.00001$ ) (Figure 3 ). We also assessed the effect of BMI on maternal leptin level by subgroup analysis. Plasma leptin concentration remained significantly elevated in GDM patients compared to their BMI matched control subjects $(P<0.00001$, [WMD] $=7.14 \mathrm{ng} / \mathrm{mL}, 95 \%$ CI $[4.00$, $10.28] \mathrm{ng} / \mathrm{mL})$.

3.5. Serum Adiponectin Concentration and GDM. Adiponectin measurements of 560 GDM patients and 781 controls were extracted from 15 studies with 17 comparisons, as Thyfault et al. divided the GDM patients into three groups. There was a significantly decreased adiponectin level in GDM patients compared to controls with an overall WMD of $-2.85 \mu \mathrm{g} / \mathrm{mL}$ (95\% CI [-3.64, -2.06], $P<0.00001)$ (Figure 4). Subgroup analysis showed that serum adiponectin concentration remained significantly lower in GDM patients compared to their BMI matched control subjects $(P<0.00001$, [WMD] $=$ $-2.66 \mu \mathrm{g} / \mathrm{mL}, 95 \%$ CI $[-2.85,-2.48] \mu \mathrm{g} / \mathrm{mL})$.

\section{Discussion}

To the best of our knowledge, this is the first systematic review to address the correlation of maternal serum concentrations of three cytokines (TNF- $\alpha /$ leptin/adiponectin) and GDM. Findings of the meta-analysis confirmed increased levels of TNF- $\alpha$ and leptin and a decreased level of adiponectin in GDM patients compared with normal pregnancies, suggesting that imbalance in the expression of pro- and 


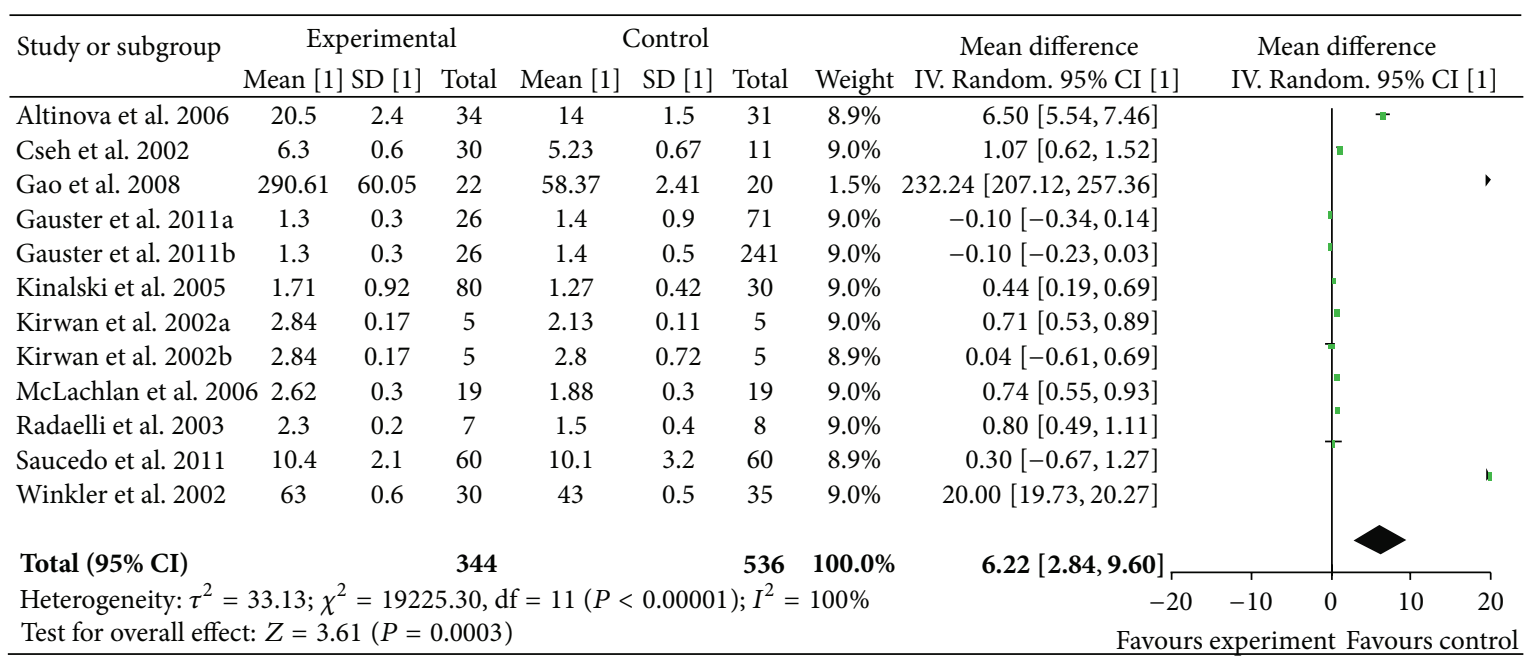

FIGURE 2: Mean difference (MD) and 95\% CI of individual studies and pooled data for the association of maternal concentration of TNF- $\alpha$ with GDM risk. Positive values denote higher in GDM patients; negative values denote higher in healthy control subjects.

\begin{tabular}{|c|c|c|c|c|c|c|c|c|c|c|}
\hline \multirow{2}{*}{ Study or subgroup } & \multicolumn{3}{|c|}{ Experimental } & \multicolumn{3}{|c|}{ Control } & \multicolumn{2}{|r|}{ Mean difference } & \multirow{2}{*}{\multicolumn{2}{|c|}{$\begin{array}{l}\text { Mean difference } \\
\text { IV. Random. 95\% CI [1] }\end{array}$}} \\
\hline & Mean & $\mathrm{SD}$ & Total & Mean & SD & Total & Weight & IV. Random. 95\% CI [1] & & \\
\hline Chen et al. 2010 & 42.55 & 7.4 & 20 & 29 & 8.74 & 20 & $5.8 \%$ & $13.55[8.53,18.57]$ & & \\
\hline Cseh et al. 2002 & 40.41 & 24.52 & 30 & 33.15 & 22.04 & 11 & $2.1 \%$ & $7.26[-8.44,22.96]$ & & \\
\hline Festa et al. 1999 & 21.9 & 7 & 55 & 24.4 & 11.9 & 166 & $6.8 \%$ & $-2.50[-5.09,0.09]$ & & \\
\hline Gao et al. 2008 & 22.64 & 5.8 & 22 & 8.88 & 2.41 & 20 & $6.8 \%$ & $13.76[11.12,16.40]$ & & - \\
\hline Gauster et al. 2011a & 57.9 & 32.4 & 26 & 32.6 & 20.4 & 71 & $2.7 \%$ & $25.30[11.97,38.63]$ & & \\
\hline Gauster et al. 2011b & 57.9 & 32.4 & 26 & 63.6 & 32.5 & 170 & $2.6 \%$ & $-5.70[-19.08,7.68]$ & & \\
\hline Georgiou et al. 2008 & 21.1 & 17.3 & 14 & 18.2 & 12.6 & 14 & $3.3 \%$ & $2.90[-8.31,14.11]$ & & \\
\hline Horosz et al. 2011 & 24.14 & 12.77 & 86 & 21.34 & 11.67 & 48 & $6.1 \%$ & $2.80[-1.46,7.06]$ & & \\
\hline Kautzky et al. 2001 & 24.9 & 1.6 & 55 & 18.2 & 1.5 & 25 & $7.2 \%$ & $6.70[5.98,7.42]$ & & \\
\hline Kirwan et al. 2002a & 44.1 & 12.2 & 5 & 11.6 & 1.6 & 5 & $3.4 \%$ & $32.50[21.71,43.29]$ & & \\
\hline Kirwan et al. 2002b & 44.1 & 12.2 & 5 & 36.4 & 12 & 5 & $2.3 \%$ & $7.70[-7.30,22.70]$ & & \\
\hline Kleiblova et al. 2009 & 39.6 & 8.11 & 10 & 21.8 & 2.72 & 13 & $5.7 \%$ & $17.80[12.56,23.04]$ & & \\
\hline McLachlan et al. 2006 & 32.2 & 3.9 & 19 & 23 & 2.3 & 19 & $6.9 \%$ & $9.20[7.16,11.24]$ & & $\mathrm{r}$ \\
\hline Mokhtari et al. 2011 & 9.89 & 7.764 & 26 & 13.8 & 10.32 & 22 & $5.7 \%$ & $-3.91[-9.15,1.33]$ & " & \\
\hline Okereke et al. 2004 & 44.1 & 27.2 & 7 & 32.2 & 26 & 8 & $0.9 \%$ & $11.90[-15.13,38.93]$ & & \\
\hline Radaelli et al. 2003 & 45 & 3.5 & 7 & 28.3 & 5.5 & 8 & $6.0 \%$ & $16.70[12.09,21.31]$ & & \\
\hline Ranheim et al. 2004 & 23.3 & 1.7 & 22 & 22.7 & 1.3 & 29 & $7.2 \%$ & $0.60[-0.25,1.45]$ & & \\
\hline Saucedo et al. 2011 & 22.7 & 4.9 & 60 & 23.3 & 11.7 & 60 & $6.6 \%$ & $-0.60[-3.81,2.61]$ & & \\
\hline Vitoratos et al. 2001 & 16.52 & 5.07 & 17 & 10.61 & 1.47 & 17 & $6.8 \%$ & $5.91[3.40,8.42]$ & & 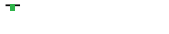 \\
\hline Yilmaz et al. 2010 & 37.64 & 15.42 & 56 & 31.41 & 14.98 & 42 & $5.3 \%$ & $6.23[0.16,12.30]$ & & \\
\hline \multirow{2}{*}{\multicolumn{8}{|c|}{ Heterogeneity: $\tau^{2}=26.90 ; \chi^{2}=333.69, \mathrm{df}=19(P<0.00001) ; I^{2}=94 \%$}} & $7.52[4.79,10.25]$ & & $\bullet$ \\
\hline & & & & & & & & -50 & -25 & 25 \\
\hline \multicolumn{8}{|c|}{ Test for overall effect: $Z=5.40(P<0.00001)$} & \multicolumn{3}{|c|}{ Favours experiment Favours contro } \\
\hline
\end{tabular}

FIGURE 3: Mean difference (MD) and 95\% CI of individual studies and pooled data for the association of maternal concentration of leptin with GDM risk. Positive values denote higher in GDM patients; negative values denote higher in healthy control subjects.

anti-inflammatory cytokines may contribute to impaired glucose homeostasis in GDM.

Inflammatory cytokines, including TNF- $\alpha$, IL- 6 , and IL8 , have been involved in the pathogenesis of insulin resistance. Among these inflammatory cytokines, the evidence that insulin resistance is linked to TNF- $\alpha$, but not IL- 6 and IL8 , is well established. Although type $2 \mathrm{DM}$ is associated with IL-6 polymorphism [41] and higher plasma concentrations of IL-6 [42], there is no direct evidence for an association between IL-6 expression and pregnancy-induced insulin resistance. Additionally, TNF- $\alpha$ has been demonstrated to be the most significant predictor of pregnancy-induced insulin resistance and be more highly synthesized and released from the placenta compared with IL-6 or IL- 8 [43]. Hence, TNF$\alpha$ is more likely to exert crucial effects on insulin resistance during pregnancy.

Adipokines, such as leptin, adiponectin, and resistin, may also be involved in the pathogenesis of insulin resistance. Although the leptin is produced mainly by adipocytes, there is strong evidence that the placenta, rather than maternal adipose tissue, contributes to the rise in maternal leptin concentrations during pregnancy [44]. Pregnancy is 


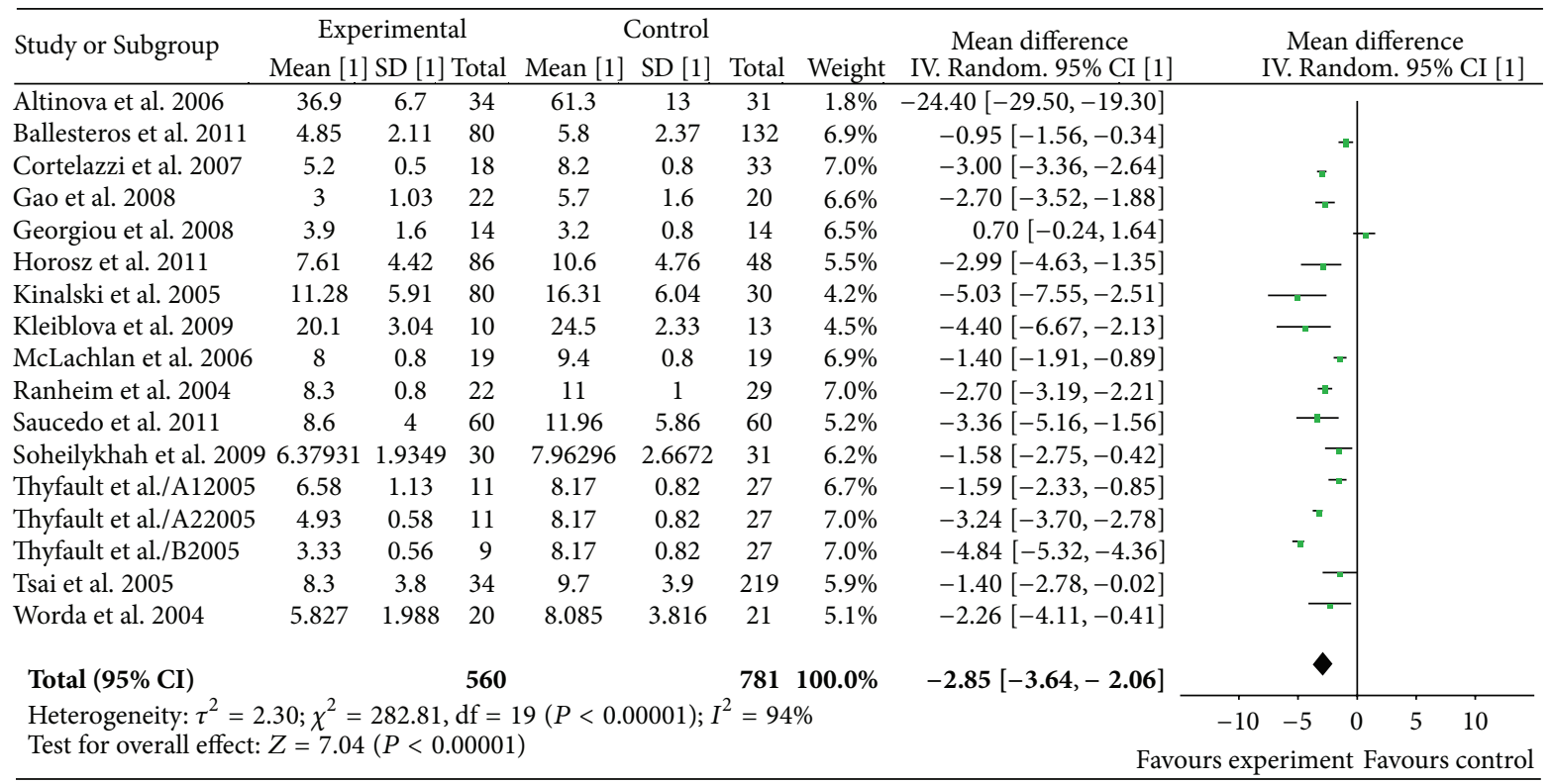

Figure 4: Mean difference (MD) and 95\% CI of individual studies and pooled data for the association of maternal concentration of adiponectin with GDM risk. Positive values denote higher in GDM patients; negative values denote higher in healthy control subjects.

considered a leptin resistant state; circulating leptin levels are two- to threefold higher concentrations as compared to nonpregnancy condition. Results on circulating leptin in patients with GDM have been inconsistent. Thus, levels of the leptin are not altered in patients with GDM as compared to healthy pregnant women in some reports $[18,23]$, whereas other authors demonstrate elevated levels of leptin in women with GDM $[9,14]$. And a strong linear correlation between increased maternal plasma leptin and increased risk of GDM has been found [14]. Resistin, an adipocyte-derived cytokine, is poorly produced by the placenta [45]. Despite elevated resistin levels in GDM, the independent relationship between insulin resistance and circulating resistin concentrations cannot be established [46]. Adiponectin, one of a smaller number of anti-inflammatory factors, is considered to have beneficial effects on insulin sensitivity. Low adiponectin serum levels are demonstrated to be linked with type $2 \mathrm{DM}$ and insulin resistance [47]. Moreover, Lain et al. show that women with low levels of first trimester adiponectin are more likely to be diagnosed with GDM as compared to women with higher adiponectin levels [48], suggesting that downregulation of adiponectin in the first trimester of pregnancy might be a predictor of GDM. In view of these findings, leptin and adiponectin are likely to be more important in the pathogenesis of pregnancy-associated insulin resistance as compared to resistin.

TNF- $\alpha$, leptin, and adiponectin have been demonstrated to be produced in placenta $[49,50]$. In vitro, most of the placental TNF- $\alpha$ and leptin are released into the maternal circulation, which contributes to the rise in maternal TNF- $\alpha$ and leptin concentrations during pregnancy; little is released to the fetal side [4]. Release of TNF- $\alpha$ and leptin from placenta during pregnancy is considered to be a diabetogenic factor exacerbating insulin resistance. TNF- $\alpha$ is reported to increase with gestational progression and to be strongly associated with insulin sensitivity in normal pregnancy [4]. When placentas obtained from GDM patients are cultured under high glucose conditions, the accumulation of TNF- $\alpha$ in media is significantly greater compared with placentas incubated in normal glucose concentrations [51]. Animal models characterized by reduced-leptin signaling show hyperphagia, obesity, and insulin resistance [52], and leptin management improves insulin sensitivity and glucose metabolism in these models [53]. Additionally, positive leptin relation to fasting glucose and insulin was shown in studies in the presence of elevated leptin in GDM. Adiponectin is thought to have beneficial effects on insulin sensitivity and anti-inflammatory activities. Investigators have reported that depressed maternal adiponectin concentrations, measured in early pregnancy or at delivery, were found in GDM women compared with nondiabetic pregnant women. Therefore, it is reasonable to speculate that these cytokines can be a cause of impaired glucose metabolism in GDM. That may indicate possible cytokines influence on fetal growth.

GDM is characterized by an amplification of the lowgrade inflammation already existing in normal pregnancy [54]. The data presented in this study demonstrate that the maternal proinflammatory cytokines, TNF- $\alpha$ and leptin, are elevated in GDM patients as compared to normal pregnancy; but the anti-inflammatory adiponectin is depressed, which strengths the clinical evidence that GDM is accompanied by exaggerated inflammatory response. Increased circulating concentrations of TNF- $\alpha$ cause a chronic inflammatory environment and enhance leptin production. Conversely, leptin increases the production of TNF- $\alpha$ and IL6 by monocytes [55] and stimulates the production of CCchemokine ligands [56]. Thus, a vicious circle develops, resulting in an aggravated inflammatory situation, which 
might worsen metabolic dysfunction in GDM. Furthermore, TNF- $\alpha$ and other proinflammatory mediators suppress the production of adiponectin by adipocytes [57]. Because of the insulin-sensitizing effects, low levels of adiponectin might further aggravate insulin resistance in GDM. To summarise, GDM may arise in part from an amplification of inflammatory situation. It is the upregulation of proinflammatory mediators, that is, TNF- $\alpha$ and leptin, and the downregulation of anti-inflammatory molecules, that is, adiponectin, that lead to the development of chronic inflammatory state and contribute to the hyperinsulinemia in GDM.

It is well known that obesity is strongly associated with inflammation, which contributes to insulin resistance [3]. Many of the studies included in the meta-analysis found that patients with GDM had significantly higher TNF- $\alpha$ and leptin concentrations and lower adiponectin concentrations than control women. The differences remained statistically significant after adjusting for BMI in some studies, but not all. Moreover, some studies found a significant positive correlation between BMI values and levels of TNF- $\alpha$ and leptin and an inverse correlation between BMI and adiponectin levels in GDM $[9,14,16,33]$. So, subgroup analysis taking in consideration the effect of BMI values on maternal cytokine levels was performed in this meta-analysis. We categorized the studies according to their designs into two classes with respect to BMI matched and BMI not matched between controls and GDM groups. We found that plasma TNF- $\alpha$ and leptin concentrations remained significantly elevated in GDM patients compared to their BMI matched control subjects, and adiponectin concentration remained significantly depressed. These data suggest that maternal weight in GDM seems to have less important role in modifying cytokine levels.

Limitations of this meta-analysis should be acknowledged. First, studies on cytokine concentrations and GDM that provided results in form other than mean $( \pm S D)$ were ruled out in our analysis as methodological reason, although most of them observed higher median cytokine levels in GDM patients compared with control subjects. Second, concentrations provided by the included studies vary greatly with a maximum of 200-fold discrepancy between that detected by Gao et al. and that detected by Gauster et al. High degree of heterogeneity in three outcomes of concentration meta-analysis is not surprising due to different assay kits, procedures, operations for cytokine detection, and other unperceived variables. Although regression analyses to further explore sources of heterogeneity were not conducted in our study because of the power limitation of software, variety in assay kits was considered to have central contribution to the heterogeneity. Therefore, random effects model was adopted in our meta-analysis as it gives a larger $P$ value and wider confidence intervals. Third, some factors that can alter maternal serum cytokine levels (e.g., maternal weight, smoking, insulin therapy, and labor onset) and other confounding factors cannot be excluded. Finally, it is very important to keep publication bias in mind when meta-analysis relies on previously published studies because positive results are more likely to be published than negative results.

\section{Conclusion}

This meta-analysis confirmed the increased levels of TNF$\alpha$ and leptin and the decreased level of adiponectin in GDM, suggesting that increase in proinflammatory cytokines and decrease in anti-inflammatory factors may contribute to impaired glucose homeostasis in GDM and indicating that these cytokines might be of predictive value in GDM diagnosis. However, further studies are required to investigate the mechanism of the alteration of the three cytokines.

\section{Conflict of Interests}

The authors declare that there is no conflict of interests regarding the publication of this paper.

\section{Acknowledgment}

The authors thank the authors of all original articles who responded to request for data or clarifications.

\section{References}

[1] S. G. Gabbe, "Gestational diabetes mellitus," The New England Journal of Medicine, vol. 315, no. 16, pp. 1025-1026, 1986.

[2] B. E. Metzger, T. A. Buchanan, D. R. Coustan et al., "Summary and recommendations of the fifth international workshopconference on gestational diabetes mellitus," Diabetes Care, vol. 30, supplement 2, pp. S251-S260, 2007.

[3] G. S. Hotamisligil, "Inflammation and metabolic disorders," Nature, vol. 444, no. 7121, pp. 860-867, 2006.

[4] J. P. Kirwan, S. Hauguel-de Mouzon, J. Lepercq et al., "TNF- $\alpha$ is a predictor of insulin resistance in human pregnancy," Diabetes, vol. 51, no. 7, pp. 2207-2213, 2002.

[5] J. Lepercq, M. Cauzac, N. Lahlou et al., "Overexpression of placental leptin in diabetic pregnancy: a critical role for insulin," Diabetes, vol. 47, no. 5, pp. 847-850, 1998.

[6] N. Ouchi, S. Kihara, T. Funahashi, Y. Matsuzawa, and K. Walsh, "Obesity, adiponectin and vascular inflammatory disease," Current Opinion in Lipidology, vol. 14, no. 6, pp. 561-566, 2003.

[7] T. Radaelli, A. Varastehpour, P. Catalano, and S. Hauguelde Mouzon, "Gestational diabetes induces placental genes for chronic stress and inflammatory pathways," Diabetes, vol. 52, no. 12, pp. 2951-2958, 2003.

[8] K. T. Uysal, S. M. Wiesbrock, M. W. Marino, and G. S. Hotamisligil, "Protection from obesity-induced insulin resistance in mice lacking TNF- $\alpha$ function," Nature, vol. 389, no. 6651, pp. 610-614, 1997.

[9] K. Cseh, É. Baranyi, Z. Melczer et al., “The pathophysiological influence of leptin and the tumor necrosis factor system on maternal insulin resistance: negative correlation with anthropometric parameters of neonates in gestational diabetes," Gynecological Endocrinology, vol. 16, no. 6, pp. 453-460, 2002.

[10] T. Yamauchi, J. Kamon, Y. Minokoshi et al., "Adiponectin stimulates glucose utilization and fatty-acid oxidation by activating AMP-activated protein kinase," Nature Medicine, vol. 8, no. 11, pp. 1288-1295, 2002.

[11] A. H. Berg and P. E. Scherer, "Adipose tissue, inflammation, and cardiovascular disease," Circulation Research, vol. 96, no. 9, pp. 939-949, 2005. 
[12] A. Liberati, D. G. Altman, J. Tetzlaff et al., "The PRISMA statement for reporting systematic reviews and meta-analyses of studies that evaluate health care interventions: explanation and elaboration," PLoS Medicine, vol. 6, no. 7, Article ID e1000100, 2009.

[13] A. E. Altinova, F. Toruner, N. Bozkurt et al., "Circulating concentrations of adiponectin and tumor necrosis factor- $\alpha$ in gestational diabetes mellitus," Gynecological Endocrinology, vol. 23, no. 3, pp. 161-165, 2007.

[14] X. Gao, H. Yang, and Y. Zhao, "Variations of tumor necrosis factor- $\alpha$, leptin and adiponectin in mid-trimester of gestational diabetes mellitus," Chinese Medical Journal, vol. 121, no. 8, pp. 701-705, 2008.

[15] M. Gauster, U. Hiden, M. Van Poppel et al., "Dysregulation of placental endothelial lipase in obese women with gestational diabetes mellitus," Diabetes, vol. 60, no. 10, pp. 2457-2464, 2011.

[16] M. Kinalski, B. Telejko, M. Kuźmicki, A. Krętowski, and I. Kinalska, "Tumor necrosis factor alpha system and plasma adiponectin concentration in women with gestational diabetes," Hormone and Metabolic Research, vol. 37, no. 7, pp. 450-454, 2005.

[17] K. A. McLachlan, D. O’Neal, A. Jenkins, and F. P. Alford, "Do adiponectin, TNF $\alpha$, leptin and CRP relate to insulin resistance in pregnancy? Studies in women with or without gestational diabetes, during and after pregnancy," Diabetes/Metabolism Research and Reviews, vol. 22, no. 2, pp. 131-138, 2006.

[18] R. Saucedo, A. Zarate, L. Basurto et al., "Relationship between circulating adipokines and insulin resistance during pregnancy and postpartum in women with gestational diabetes," Archives of Medical Research, vol. 42, no. 4, pp. 318-323, 2011.

[19] G. Winkler, K. Cseh, É. Baranyi et al., "Tumor necrosis factor system in insulin resistance in gestational diabetes," Diabetes Research and Clinical Practice, vol. 56, no. 2, pp. 93-99, 2002.

[20] D. Chen, G. Xia, P. Xu, and M. Dong, "Peripartum serum leptin and soluble leptin receptor levels in women with gestational diabetes," Acta Obstetricia et Gynecologica Scandinavica, vol. 89, no. 12, pp. 1595-1599, 2010.

[21] A. Festa, N. Shnawa, W. Krugluger, P. Hopmeier, G. Schernthaner, and S. M. Haffner, "Relative hypoleptinaemia in women with mild gestational diabetes mellitus," Diabetic Medicine, vol. 16, no. 8, pp. 656-662, 1999.

[22] H. M. Georgiou, M. Lappas, G. M. Georgiou et al., "Screening for biomarkers predictive of gestational diabetes mellitus," Acta Diabetologica, vol. 45, no. 3, pp. 157-165, 2008.

[23] E. Horosz, D. A. Bomba-Opon, M. Szymanska, and M. Wielgos, "Third trimester plasma adiponectin and leptin in gestational diabetes and normal pregnancies," Diabetes Research and Clinical Practice, vol. 93, no. 3, pp. 350-356, 2011.

[24] A. Kautzky-Willer, G. Pacini, A. Tura et al., "Increased plasma leptin in gestational diabetes," Diabetologia, vol. 44, no. 2, pp. 164-172, 2001.

[25] P. Kleiblova, I. Dostalova, M. Bartlova et al., "Expression of adipokines and estrogen receptors in adipose tissue and placenta of patients with gestational diabetes mellitus," Molecular and Cellular Endocrinology, vol. 314, no. 1, pp. 150-156, 2010.

[26] M. Mokhtari, M. Hashemi, M. Yaghmaei, M. Naderi, A. Shikhzadeh, and S. Ghavami, "Evaluation of the serum leptin in normal pregnancy and gestational diabetes mellitus in Zahedan, southeast Iran," Archives of Gynecology and Obstetrics, vol. 284, no. 3, pp. 539-542, 2011.

[27] N. Vitoratos, E. Salamalekis, D. Kassanos et al., "Maternal plasma leptin levels and their relationship to insulin and glucose in gestational-onset diabetes," Gynecologic and Obstetric Investigation, vol. 51, no. 1, pp. 17-21, 2001.

[28] N. C. Okereke, L. Huston-Presley, S. B. Amini, S. Kalhan, and P. M. Catalano, "Longitudinal changes in energy expenditure and body composition in obese women with normal and impaired glucose tolerance," The American Journal of Physiology-Endocrinology and Metabolism, vol. 287, no. 3, pp. E472-E479, 2004.

[29] T. Ranheim, F. Haugen, A. C. Staff, K. Braekke, N. K. Harsem, and C. A. Drevon, "Adiponectin is reduced in gestational diabetes mellitus in normal weight women," Acta Obstetricia et Gynecologica Scandinavica, vol. 83, no. 4, pp. 341-347, 2004.

[30] O. Yilmaz, M. Kucuk, A. Ilgin, and M. Dagdelen, "Assessment of insulin sensitivity/resistance and their relations with leptin concentrations and anthropometric measures in a pregnant population with and without gestational diabetes mellitus," Journal of Diabetes and its Complications, vol. 24, no. 2, pp. 109$114,2010$.

[31] M. Ballesteros, I. Simón, J. Vendrell et al., "Maternal and cord blood adiponectin multimeric forms in gestational diabetes mellitus: a prospective analysis," Diabetes Care, vol. 34, no. 11, pp. 2418-2423, 2011.

[32] D. Cortelazzi, S. Corbetta, S. Ronzoni et al., "Maternal and foetal resistin and adiponectin concentrations in normal and complicated pregnancies," Clinical Endocrinology, vol. 66, no. 3, pp. 447-453, 2007.

[33] S. Soheilykhah, M. Mohammadi, M. Mojibian et al., "Maternal serum adiponectin concentration in gestational diabetes," Gynecological Endocrinology, vol. 25, no. 9, pp. 593-596, 2009.

[34] J. P. Thyfault, E. M. Hedberg, R. M. Anchan et al., "Gestational diabetes is associated with depressed adiponectin levels," Journal of the Society for Gynecologic Investigation, vol. 12, no. 1, pp. 41-55, 2005.

[35] P. Tsai, C. Yu, S. Hsu et al., "Maternal plasma adiponectin concentrations at 24 to 31 weeks of gestation: negative association with gestational diabetes mellitus," Nutrition, vol. 21, no. 11-12, pp. 1095-1099, 2005.

[36] C. Worda, H. Leipold, C. Gruber, A. Kautzky-Willer, M. Knöfler, and D. Bancher-Todesca, "Decreased plasma adiponectin concentrations in women with gestational diabetes mellitus," The American Journal of Obstetrics and Gynecology, vol. 191, no. 6, pp. 2120-2124, 2004.

[37] M. W. Carpenter and D. R. Coustan, "Criteria for screening tests for gestational diabetes," The American Journal of Obstetrics and Gynecology, vol. 144, no. 7, pp. 768-773, 1982.

[38] A. Stang, "Critical evaluation of the Newcastle-Ottawa scale for the assessment of the quality of nonrandomized studies in metaanalyses," European Journal of Epidemiology, vol. 25, no. 9, pp. 603-605, 2010

[39] F. Faul, E. Erdfelder, A. Lang, and A. Buchner, "G* Power 3: a flexible statistical power analysis program for the social, behavioral, and biomedical sciences," Behavior Research Methods, vol. 39, no. 2, pp. 175-191, 2007.

[40] F. Song, T. A. Sheldon, A. J. Sutton, K. R. Abrams, and D. R. Jones, "Methods for exploring heterogeneity in meta-analysis," Evaluation and the Health Professions, vol. 24, no. 2, pp. 126-151, 2001.

[41] J. Fernández-Real, M. Broch, J. Vendrell et al., "Interleukin-6 gene polymorphism and insulin sensitivity," Diabetes, vol. 49, no. 3, pp. 517-520, 2000. 
[42] P. A. Kern, S. Ranganathan, C. Li, L. Wood, and G. Ranganathan, "Adipose tissue tumor necrosis factor and interleukin-6 expression in human obesity and insulin resistance," The American Journal of Physiology_Endocrinology and Metabolism, vol. 280, no. 5, pp. E745-E751, 2001.

[43] M. Lappas, M. Permezel, and G. E. Rice, "Release of proinflammatory cytokines and 8-isoprostane from placenta, adipose tissue, and skeletal muscle from normal pregnant women and women with gestational diabetes mellitus," Journal of Clinical Endocrinology and Metabolism, vol. 89, no. 11, pp. 5627-5633, 2004.

[44] S. Bi, O. Gavrilova, D. Gong, M. M. Mason, and M. Reitman, "Identification of a placental enhancer for the human leptin gene," Journal of Biological Chemistry, vol. 272, no. 48, pp. 30583-30588, 1997.

[45] M. Lappas, K. Yee, M. Permezel, and G. E. Rice, "Release and regulation of leptin, resistin and adiponectin from human placenta, fetal membranes, and maternal adipose tissue and skeletal muscle from normal and gestational diabetes mellituscomplicated pregnancies," Journal of Endocrinology, vol. 186, no. 3, pp. 457-465, 2005.

[46] M. Kuzmicki, B. Telejko, J. Szamatowicz et al., "High resistin and interleukin-6 levels are associated with gestational diabetes mellitus," Gynecological Endocrinology, vol. 25, no. 4, pp. 258263, 2009.

[47] N. Rasouli and P. A. Kern, "Adipocytokines and the metabolic complications of obesity," Journal of Clinical Endocrinology and Metabolism, vol. 93, no. 11, pp. S64-S73, 2008.

[48] K. Y. Lain, A. R. Daftary, R. B. Ness, and J. M. Roberts, "First trimester adipocytokine concentrations and risk of developing gestational diabetes later in pregnancy," Clinical Endocrinology, vol. 69, no. 3, pp. 407-411, 2008.

[49] H. L. Chen, Y. P. Yang, X. L. Hu, K. K. Yelavarthi, J. L. Fishback, and J. S. Hunt, "Tumor necrosis factor alpha mRNA and protein are present in human placental and uterine cells at early and late stages of gestation," The American Journal of Pathology, vol. 139, no. 2, pp. 327-335, 1991.

[50] H. Masuzaki, Y. Ogawa, N. Sagawa et al., "Nonadipose tissue production of leptin: leptin as a novel placenta- derived hormone in humans," Nature Medicine, vol. 3, no. 9, pp. 1029-1033, 1997.

[51] M. T. Coughlan, K. Oliva, H. M. Georgiou, J. M. H. Permezel, and G. E. Rice, "Glucose-induced release of tumour necrosis factor-alpha from human placental and adipose tissues in gestational diabetes mellitus," Diabetic Medicine, vol. 18, no. 11, pp. 921-927, 2001.

[52] Y. Zhang, R. Proenca, M. Maffei et al., "Positional cloning of the mouse obese gene and its human homologue," Nature, vol. 372, pp. 425-432, 1994.

[53] J. L. Halaas, C. Boozer, J. Blair-West, N. Fidahusein, D. A. Denton, and J. M. Friedman, "Physiological response to longterm peripheral and central leptin infusion in lean and obese mice," Proceedings of the National Academy of Sciences of the United States of America, vol. 94, no. 16, pp. 8878-8883, 1997.

[54] L. A. Barbour, C. E. McCurdy, T. L. Hernandez, J. P. Kirwan, P. M. Catalano, and J. E. Friedman, "Cellular mechanisms for insulin resistance in normal pregnancy and gestational diabetes," Diabetes Care, vol. 30, supplement 2, pp. S112-S119, 2007.

[55] J. Santos-Alvarez, R. Goberna, and V. Sánchez-Margalet, "Human leptin stimulates proliferation and activation of human circulating monocytes," Cellular Immunology, vol. 194, no. 1, pp. 6-11, 1999.

[56] N. Kiguchi, T. Maeda, Y. Kobayashi, Y. Fukazawa, and S. Kishioka, "Leptin enhances CC-chemokine ligand expression in cultured murine macrophage," Biochemical and Biophysical Research Communications, vol. 384, no. 3, pp. 311-315, 2009.

[57] M. Fasshauer, J. Klein, S. Neumann, M. Eszlinger, and R. Paschke, "Hormonal regulation of adiponectin gene expression in 3T3-L1 adipocytes," Biochemical and Biophysical Research Communications, vol. 290, no. 3, pp. 1084-1089, 2002. 


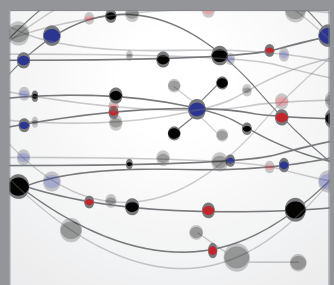

The Scientific World Journal
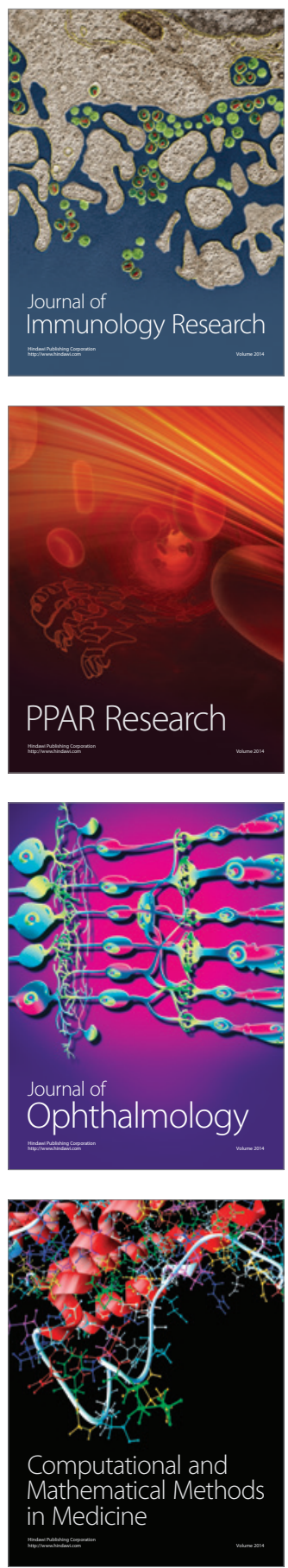

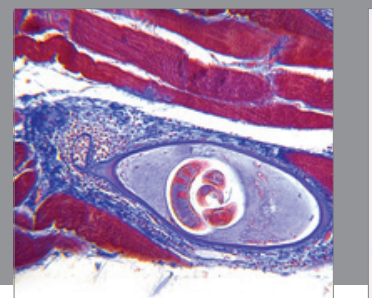

Gastroenterology

Research and Practice
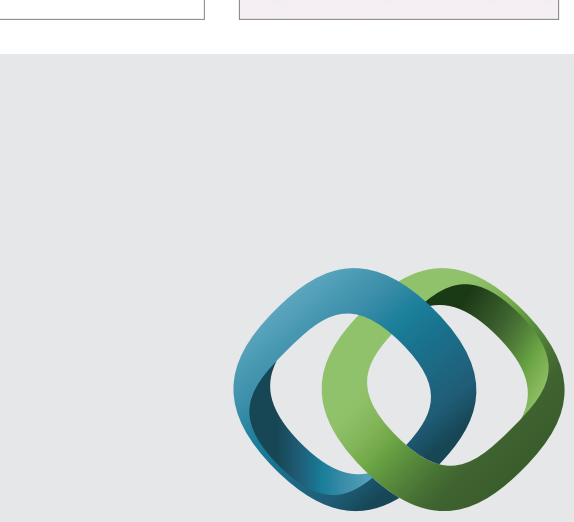

\section{Hindawi}

Submit your manuscripts at

http://www.hindawi.com
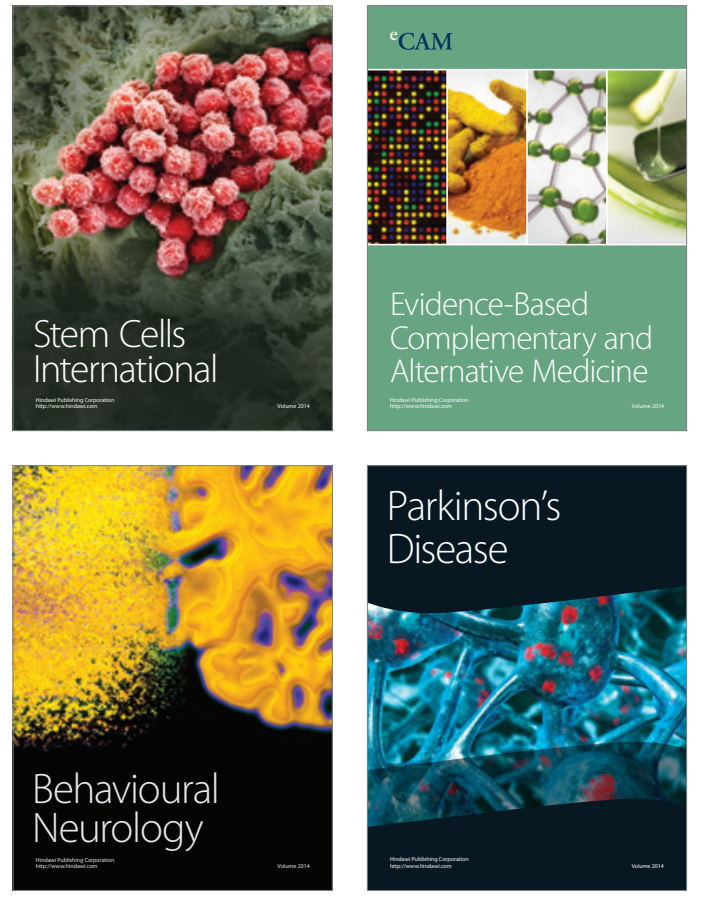
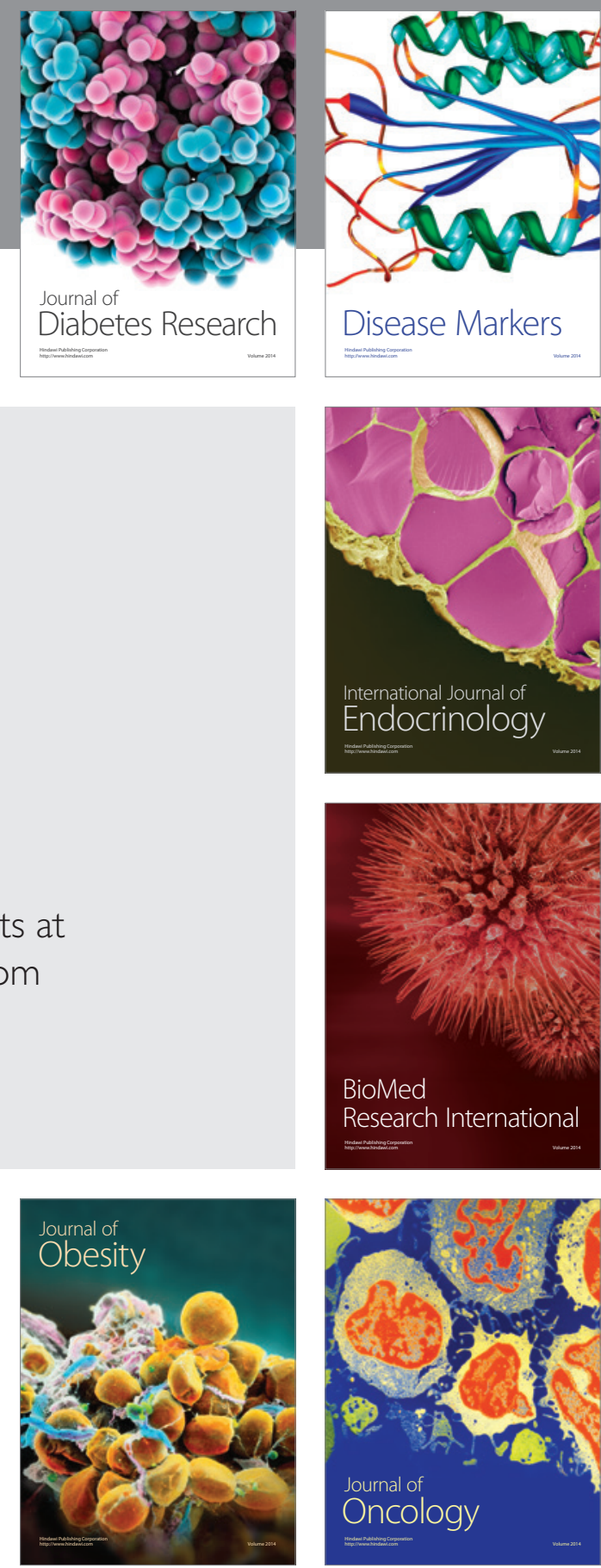

Disease Markers
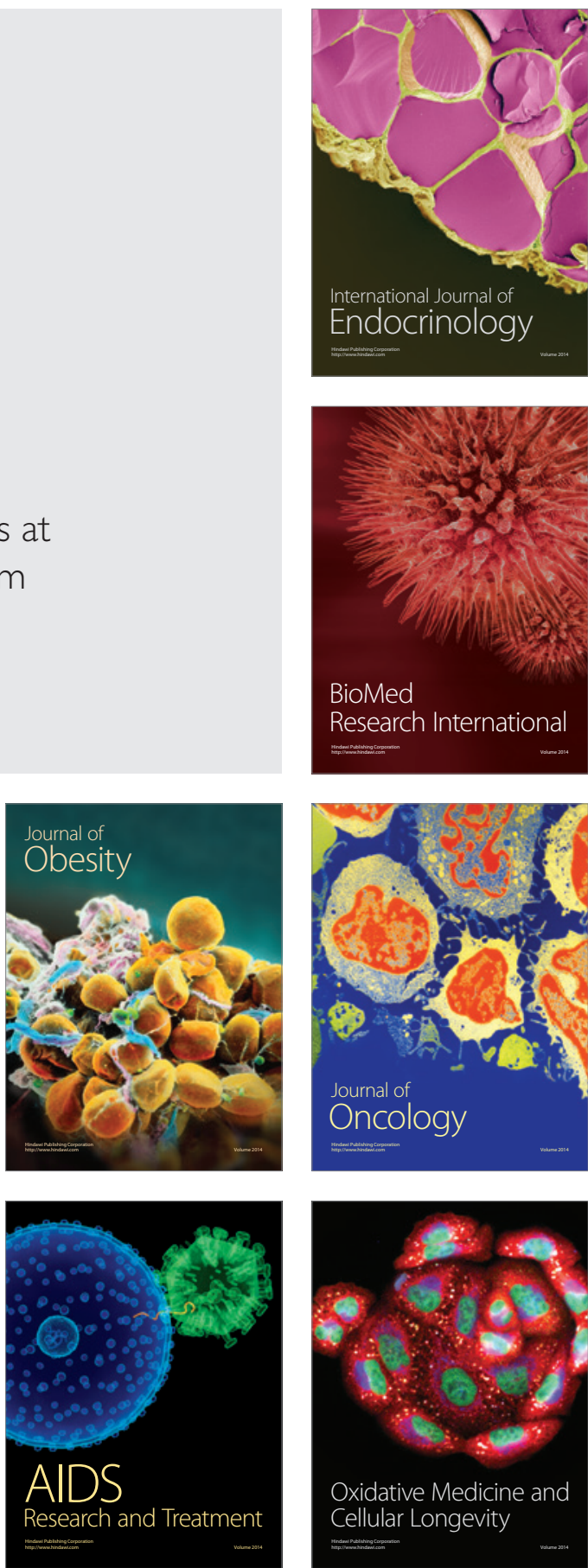